\title{
A Novel Step-Up Power Converter Configuration for Solar Energy Application
}

\author{
Davood Ghaderi, Gokay Bayrak \\ Department of Electrical and Electronics Engineering, Bursa Technical University, \\ Bursa, Turkey \\ davood.ghaderi@btu.edu.tr
}

\begin{abstract}
Renewable Energy Sources (RES) including full cells, wind turbines, and photovoltaic panels, widely are spreading. Among all the renewable energy sources, solar power generation system tops the list. The first choice is the boost converter when the voltage step-up is the issue. But the most important subject is applying an efficient structure with high gain, cheap and quick controller circuit. Our proposed cascaded boost converter is one of such converters which consists of several cheap components such as diode, inductor, capacitor and power switch, which has same switching frequency and phase shift in comparison with conventional boost converters. In comparison with the classic cascaded boost converter, the voltage gain for the proposed structure is very high and by forming a preamplifier layer, for a duty cycle of $80 \%$ by adding only two diodes, one inductor, and one capacitor for the second block, voltage gain is increased by 5 times compared to the classic boost converter. The proposed method provides the increased output voltage along with the duty cycle. The projected strategy has been verified with the help of Matlab/Simulink. Also, a hardware implementation of the proposed converter has been done around $200 \mathrm{~W}$ by applying a Jiangyin HR-200W-24V type solar panel.
\end{abstract}

Index Terms-DC-DC converter; Renewable energy application; High gain; Boosting structure.

\section{INTRODUCTION}

Today, Renewable Energy Sources (RES) such as solar energy, and wind energy have become an alternative energy source as fossil fuels have shortened in a short time and the severe damage to the environment. However, the disadvantage of solar energy and wind energy is that they are affected by the natural conditions their efficiency changes according to these conditions. Switching mode resources can be used for many purposes, including DC-DC converters. Often, even though a DC source such as a battery is available, that's voltage is not suited to the need of the system. For example, motors which are used to drive electric cars require higher voltages than the $500 \mathrm{~V}$ field supplied with a stand-alone battery. Even if the batteries were used, the extra weight and space needed would be too large to prevent the practicality of the system. The solution is to use less battery and raise the existing voltage to the desired level using an amplifier-converter. However, if this low output

Manuscript received 5 January, 2019; accepted 28 April, 2019.

This research was funded by a grant (No. 182N06) from the Scientific Research Projects Units of Bursa Technical University, Bursa, Turkey. level can be raised to the nominal level again using a boost converter, battery life can be extended [1]-[3].

The input to a boost converter can be a DC from a network inverter, as well as from many sources such as solar panels, fuel cells, and DC generators, as well as solid waste batteries. The main areas where DC-DC power boost converters are used include the battery power transmission systems, electrical vehicles applications, power transmission for RES applications and power for communication applications [4]-[8]. In order to reduce the component count, single switch quadratic boost converters commonly are integrated. There are different designs of this structure were proposed in [3], [9]. Hence, two Zero Voltage Switching (ZVS) and Zero Current Switching (ZCS) are required in order to decrease the voltage stresses on power switches and improve the converter's efficiency. To keep the high efficiency, ZVS operation has been implemented in [1], but it has a comprehensive and complicated control structure and one more power switch. Also, using of the coupled inductors instead of classic inductors are common for high gain obtaining purposes. In this inductor, the turn ratio is employed to obtain the related voltage gain. But for acquiring higher gains, the size of the coupled inductor increases, and it can directly affect the dynamic losses in the inductor and decrease the efficiency. Furthermore, because of the leakage inductance of the coupled inductor, a clamping structure or a snubber circuit is required. The clamping or snubber topology is effective and not only can minimize the voltage stresses on switches but only it can provide a zero voltage switching application. In [9], a novel passive snubber was introduced by using an extra inductor, a capacitor, and two diodes without any extra active power switch. The main disadvantage of snubber structure is their efficiency in small rated powers applications.

Fly-back boost converter also has suggested but it has more losses in comparison with classic and quadratic boost converters because of using transformers [10].

Our study is introducing a simple and cheap cascaded boost converter without any extra power switch with the ability to provide efficient and high voltage gain. In comparison with the classic boost converter, projected converter providing 10 times greater as voltage gain approximately at the same efficiency. In the first block, a new structure has been proposed and as a result, the current value in the inductor considerably decreased in comparison 
with classic boost converter and it directly decreases the conduction losses and increases the efficiency and for the second block, a switched inductor block has been applied to enhance the voltage gain that is a critical parameter in photovoltaic applications.

\section{PROPOSED CONVERTER}

Figure 1 illustrates the conventional and our proposed cascaded boost converters. As can be seen in Fig. 1(a), there is a serial connection between two conventional boost converter whereas novel blocks have been proposed in Fig. 1(b).

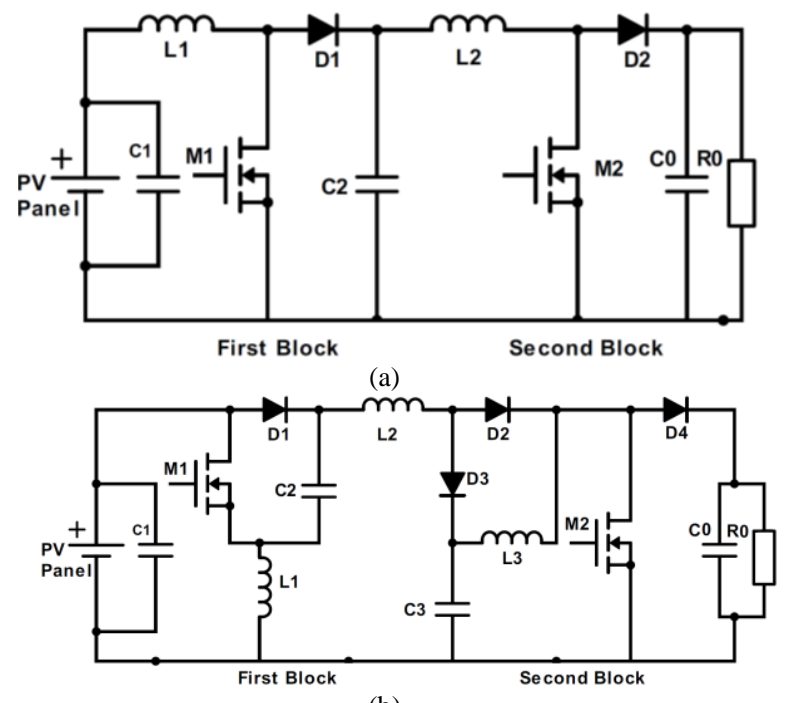

(b)

Fig. 1. Conventional (a) and proposed(b) boost converters topologies

For the first block, the configuration between inductor, diode, and capacitor has been changed. This structure can be used for both high gain and power factor correction purposes. The root mean square current value of input current to inductors in the first block considerably can be decreased for the proposed structure and it can directly reduce the conduction losses in the first block and increase the efficiency. The main role of the second block in the proposed topology is enhancing the voltage gain that is an essential factor in RES applications. By applying an extra inductor and two diodes, this block can obtain a voltage with 5 times greater than a classic boost converter in 50 percent of the duty cycle. Small signal analysis and gain calculations have been presented in this section.

\section{A. Small Signal Analysis of Structure in Switch On and Off Modes}

For Continuous Conduction Mode (CCM) operation of the proposed converter, there are four possible time intervals in a switching period. Figure 2 shows all these possibilities.

In the first time interval, both power switches are in On mode and all of $L_{1}, L_{2}$ and $L_{3}$ inductors are charging. $L_{l}$ is directly connected to the input voltage source through $\mathrm{M}_{1}$ and by considering a DC voltage at the first block's output, this DC voltage is charging the $\mathrm{L}_{2}$ by $D_{2}$ and the voltage on $C_{3}$ is discharging on $\mathrm{L}_{3}$ through $\mathrm{M}_{2}$.

For the second interval, charging of $\mathrm{L}_{1}$ will continue, while the capacitor $C_{3}$ will be charged by $L_{2}$ and $D_{3}$ and $L_{3}$ will be discharged on the load through $D_{4}$.

When the third time interval starts, the stored energy on $\mathrm{L}_{1}$ will discharge on $\mathrm{C}_{2}$ through $D_{1}$ and this process make $L_{2}$ and to charge by $D_{2}$ and $L 3$ to charge through $C_{3}$.

At the fourth station, both power switches are in Off mode. In this state, $L_{1}$ will continue to charge the $C_{2}, L_{2}$ will charge the $C_{3}$ and by this way, $L_{3}$ will supply the energy of load.
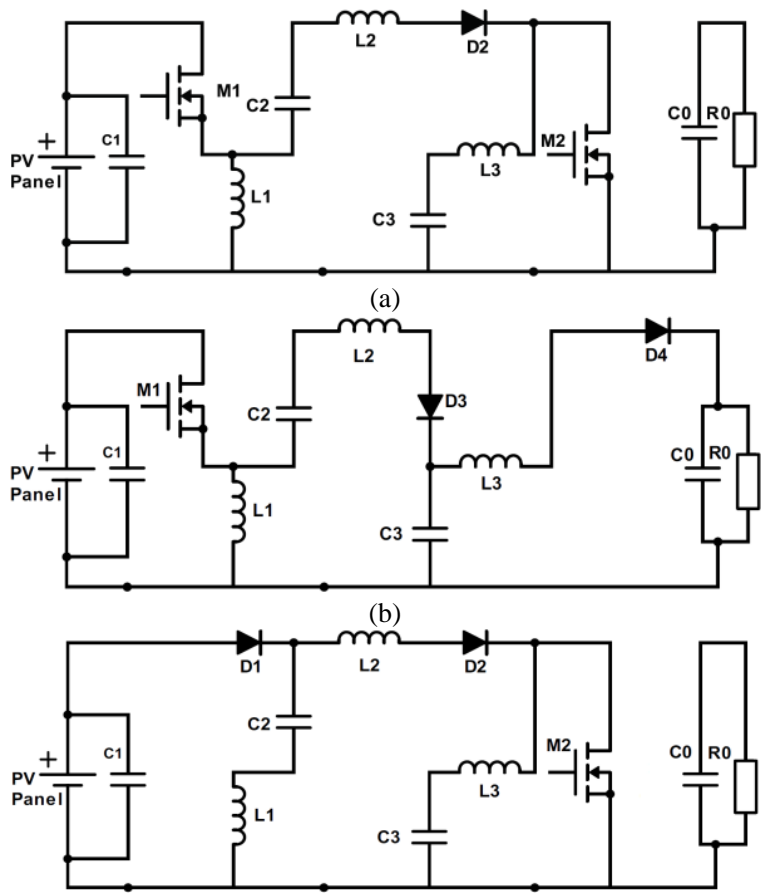

(c)

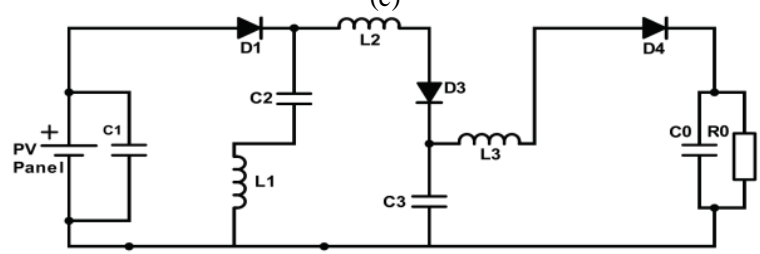

(d)

Fig. 2. Structure's different states when: a) both power switches are in On mode; b) M1 is conducting; c) M2 is conducting; d) both M1 and M2 are in Off mode.

Inductor current and capacitor voltage ripples are two important parameters in converter designing. Having a large magnitude fluctuation for current ripple directly increases the conduction losses and voltage ripple make a converter to disable producing a fixed voltage at the converter's output. Table I presents a comparison between these essential parameters for proposed and classic converters.

In Table I, $V_{C 2}$ and $V_{C 3}$ are the $C_{2}$ and $C_{3}$ capacitors voltages in steady state condition, $D_{1}$ and $D_{2}$ are the switching duty cycles of power switches $M_{1}$ and $M_{2}$ and $T_{S}$ is the switching time period. This table shows that for same voltage ripples for both structures, inductor $L_{2}$ current ripple is less for the proposed converter and this means that we can consider a smaller inductor instead of ones that should apply for the conventional type. Although we have $L_{3}$ as a new inductor in the proposed converter, the gain of this block is very high in comparison with a classic converter that can be as an alternative to make a trade-off between efficiency and voltage gain. 
TABLE I. CAPACITORS VOLTAGE AND INDUCTORS CURRENT RIPPLES FOR BOTH CONVERTERS

\begin{tabular}{|c|c|}
\hline \multicolumn{2}{|c|}{ Classic converter } \\
\hline First block & Second block \\
\hline$\Delta i_{L 1}=\frac{V_{\text {in }}}{L_{1}} D_{1} T_{s}$ & $\Delta i_{L 2}=\frac{V_{C o}-V_{C 2}}{L_{2}}\left(1-D_{2}\right) T_{s}$ \\
\hline$\Delta v_{C 2}=\frac{I_{L 1}}{C_{2}} D_{1} T_{s}$ & $\Delta v_{C o}=I_{o} D_{2} T_{s}$ \\
\hline \multicolumn{2}{|c|}{ Proposed Converter } \\
\hline First block & Second block \\
\hline$\Delta i_{L 1}=\frac{V_{\text {in }}}{L_{1}} D_{1} T_{s}$ & $\Delta i_{L 2}=\frac{\left(V_{C o}-V_{C 2}\right)-V_{i n}}{L_{2}}\left(1-D_{2}\right) T_{S}$ \\
\hline$\Delta v_{C 2}=\frac{I_{L 1}}{C_{2}} D_{1} T_{s}$ & $\Delta v_{C o}=I_{o} D_{2} T_{s}$ \\
\hline----- & $\Delta i_{L 3}=\frac{\left(V_{C o}-V_{C 3}\right)-V_{i n}}{L_{3}}\left(1-D_{2}\right) T_{S}$ \\
\hline
\end{tabular}

For the proposed structure, by considering the DC and ac parts for signals, state equations can be written to input inductors and output capacitors for both blocks as below:

$$
\begin{aligned}
& \text { 1) } \Rightarrow L_{1} \frac{d i_{L 1}(t)}{d t}=V_{i n}-V_{C 2} D_{1}^{\prime}+v_{i n}(t)-v_{C 2}(t) D_{1}^{\prime}+ \\
& +V_{C 2} d_{1}(t) \\
& \text { 2) } \Rightarrow L_{2} \frac{d i_{L 2}(t)}{d t}=V_{i n}+V_{C 2} D_{1}-V_{C 3} D_{2}^{\prime} v_{i n}(t)- \\
& -V_{C 2}(t) d_{1}(t)+V_{C 3} d_{2}(t)+v_{i n}(t)+v_{C 2}(t) D_{1}- \\
& -v_{C 2}(t) D_{2}^{\prime} \text {, } \\
& \text { 3) } \Rightarrow C_{2} \frac{d v_{C 2}(t)}{d t}=-I_{L 2} D_{1}+I_{L 1} D_{1}^{\prime}-I_{L 2} d_{1}(t)- \\
& -I_{L 2} d_{1}(t)-i_{l 2}(t) D_{1}+i_{l 1}(t) D_{1}^{\prime}, \\
& \text { 4) } \Rightarrow C_{4} \frac{d v_{C 4}(t)}{d t}=-\frac{V_{C 4}}{R}+I_{L 2} D_{2}^{\prime}-I_{L 2} d_{2}(t)-\frac{v_{C 4}(t)}{R}+ \\
& +i_{l 2}(t) D_{2}^{\prime} \text {. }
\end{aligned}
$$

In this comprehensive equation the corresponding DC parts, $D_{1}, D_{2}, D_{1}^{\prime}$ and $D_{2}^{\prime}$ are the duty cycle of power switches $\mathrm{M}_{1}$ and $\mathrm{M}_{2}$, the time interval that the $\mathrm{M}_{1}$ and $\mathrm{M}_{2}$ are Off respectively. $d_{1}(t), d_{2}(t)$ are the duty cycles in ac term and also $i_{l l}(t), i_{l 2}(2), v_{c l}(t)$ and $v_{c 2}(t)$ are ac small signal variations of $D_{1}, D_{2}, I_{L 1}, I_{L 2}, V_{C l}$ and $V_{C 2}$ respectively.

The zeros of the transfer function for this converter based on $d_{2}(t)$ to $V_{C 2}$ can be obtained as

$$
Z 1,2=\mp j \sqrt{\frac{D_{1}-1}{C_{2} L_{1}}} .
$$

This equation shows that zeros of the proposed converter are located on the imaginary axis and it results in the quick response of converter and higher overshoot of the obtained voltage in the second block's output. Table II illustrates all components conduction and switching losses for both conventional and proposed power boost converters comprehensively. In this table, $P_{c o n}$ and $P_{s w}$ are the conductive and switching losses respectively. For example, $P_{\text {conDl }}$ is the conductive losses of the power diode $D_{l}$ and $P_{s w D 2}$ is the switching losses for the diode $D_{2} . P_{L 1}$ and $P_{L 2}$ are the conductive losses on inductors. Also, $V_{f}$ is the forward voltage on diodes, $f_{s}$ is the frequency switching value and $Q_{r r 1}, Q_{r r 2}, Q_{r r 3}$ and $Q_{r r 4}$ are the electrical charges of $D_{1}, D_{2}$,

\begin{tabular}{|c|c|}
\hline Conventional Converter & Proposed Converter \\
\hline$I_{L 1}=\frac{1}{\left(1-d_{1}\right)^{*}\left(1-d_{2}\right)} \cdot \frac{V_{o}}{R}$ & $I_{L 1}=\frac{1}{\left(1-d_{1}\right)\left(1-d_{2}\right)^{2}} \cdot \frac{V_{o}}{R}$ \\
\hline$I_{L 2}=\frac{1}{\left(1-d_{2}\right)} \cdot \frac{V_{o}}{R}$ & $I_{L 2}=\frac{1}{\left(1-d_{2}\right)^{2}} \cdot \frac{V_{o}}{R}$ \\
\hline$P_{L 1}=R_{L 1}\left(i_{L 1}^{2}+\frac{\Delta i_{L 1}^{2}}{12}\right)$ & $P_{L 1}=R_{L 1}\left(i_{L 1}^{2}+\frac{\Delta i_{L 1}^{2}}{12}\right)$ \\
\hline$P_{L 2}=R_{L 2}\left(i_{L 2}^{2}+\frac{\Delta i_{L 2}^{2}}{12}\right)$ & $P_{L 2}=R_{L 2}\left(i_{L 2}^{2}+\frac{\Delta i_{L 2}^{2}}{12}\right)$ \\
\hline$P_{L 3}=0$ & $P_{L 3}=R_{L 3}\left(i_{L 3}^{2}+\frac{\Delta i_{L 3}^{2}}{12}\right)$ \\
\hline $\begin{array}{l}P_{c o n D 1}=V_{f 1} I_{L 1} D_{1}^{\prime}+ \\
+R_{o n D 1} D_{1}^{\prime}\left(I_{L 1}^{2}+\frac{\Delta i_{L 1}^{2}}{12}\right)\end{array}$ & $\begin{array}{l}P_{c o n D 1}=V_{f 1}\left(I_{L 1}+I_{L 2}\right) D_{1}^{\prime}+ \\
+R_{O n D 1} D_{1}^{\prime}\left(\left(I_{L 1}+I_{L 2}\right)^{2}+\frac{\Delta i_{L 1}^{2}}{12}\right)\end{array}$ \\
\hline $\begin{array}{l}P_{c o n D 2}=V_{f 2} I_{L 2} D_{2}^{\prime}+ \\
+R_{o n D 2} D_{2}^{\prime}\left(I_{L 2}^{2}+\frac{\Delta i_{L 2}^{2}}{12}\right)\end{array}$ & $\begin{array}{l}P_{c o n D 2}=V_{f 2}\left(I_{L 1}+I_{L 2}\right) D_{2}^{\prime}+ \\
+R_{o n D 2} D_{2}^{\prime}\left(\left(I_{L 1}+I_{L 2}\right)^{2}+\frac{\Delta i_{L 1}^{2}}{12}\right)\end{array}$ \\
\hline$P_{\text {conD3 }}=0$ & $\begin{array}{l}P_{c o n D 3}=V_{f 3}\left(I_{L 1}+I_{L 2}\right) D_{2}^{\prime}+ \\
+R_{o n D 3} D_{2}^{\prime}\left(\left(I_{L 1}+I_{L 2}\right)^{2}+\frac{\Delta i_{L 1}^{2}}{12}\right)\end{array}$ \\
\hline$P_{\text {conD4 }}=0$ & $\begin{array}{l}P_{c o n D 4}=V_{f 4} i_{L 2} D_{2}^{\prime}+ \\
+R_{o n D 4} D_{2}^{\prime}\left(I_{L 2}^{2}+\frac{\Delta i_{L 2}^{2}}{12}\right)\end{array}$ \\
\hline$P_{s w D 1}=V_{c 1} Q_{r r 1} f_{s}$ & $P_{s w D 1}=V_{c 1} Q_{r r 1} f_{s}$ \\
\hline$P_{s w D 2}=V_{c 2} Q_{r r 2} f_{s}$ & $P_{s w D 2}=V_{c 2} Q_{r r 2} f_{s}$ \\
\hline$P_{s w D 3}=0$ & $P_{s w D 3}=V_{c 3} Q_{r r 3} f_{s}$ \\
\hline$P_{s w D 3}=0$ & $P_{s w D 4}=V_{c 4} Q_{r r 4} f_{s}$ \\
\hline
\end{tabular}
$D_{3}$, and $D_{4}$ didoes' forward capacitors.

\section{B. Voltage Gain Analysis for Proposed Converter}

By considering the internal resistance of inductors, Fig. 3 illustrates an approximate model of the proposed converter. In this model, it has been assumed that all inductors with internal resistance and power semiconductors including diodes and power switch have a $V_{X}$ value as voltage drop.

TABLE II. LOSS EQUATIONS FOR BOTH CONVERTERS OPERATING IN CCM.

This value has been considered as a $V_{X}$ value for all components for more simplicity and reducing the analysis complexity. Based on charging and discharging states of inductors, mathematical evaluation for the voltage gain will appear in two different modes. For the first block, the voltage gain as same as conventional boost converter as has been given in (3)

$$
\frac{V_{O 1}}{V_{P V}}=G_{1}=\frac{1}{\left(1-D_{1}\right)} .
$$

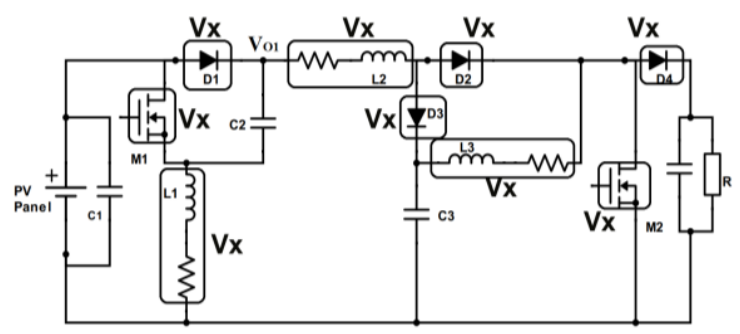

Fig. 3. The equivalent circuit for the proposed converter by considering the internal resistances and components voltage drop. 
For a power converter, the semiconductor devices, containing the power diodes and MOSFETs are the main source of losses. So, consideration of a same voltage drops on all components including the inductors and power components, will guarantee that the final DC gain will not be less than the presented equation for the DC gain of the proposed structure. So, it has been assumed that all inductors with internal resistance and power semiconductors including diodes and power switches have a $\mathrm{V}_{\mathrm{d}}$ value as voltage drop. In (3), $V_{P V}$ is the input voltage and $V_{O I}$ is the first block's output voltage that has been shown in Fig. 3. The voltage gain of this block is shown with $G_{l}$. For the second block, when power semiconductor switch is in ON and OFF modes, the voltage across inductor $L_{2}$ will be equal with

$$
\begin{gathered}
\left(V_{O 1}-3 V_{x}\right) D_{2}+\left(V_{P V}-V_{C 3}-2 V_{x}\right)\left(1-D_{2}\right)=0 \\
\Rightarrow V_{C 3}=V_{O 1}\left(\frac{1}{1-D_{2}}\right)-V_{x}\left(\frac{2+D_{2}}{1-D_{2}}\right)
\end{gathered}
$$

where $D_{2}$ is for a time interval that the switch is in on mode and $\left(1-D_{2}\right)$ is for the off state of MOSFET. Also, the voltage drops on inductor $L_{3}$ for the switch on and off intervals can be calculated as (5)

$$
\begin{gathered}
\left(V_{C 3}-2 V_{x}\right) D_{2}+\left(V_{C 3}-V_{O}-2 V_{x}\right)\left(1-D_{2}\right)=0 \\
\Rightarrow V_{O}=V_{C 3}\left(\frac{1}{1-D_{2}}\right)-V_{x}\left(\frac{2}{1-D_{2}}\right)
\end{gathered}
$$

where $\mathrm{V}_{\mathrm{O}}$ is the output voltage of the proposed converter. By replacing the (4) into (5), the voltage gain of the proposed structure can be calculated

$$
\begin{gathered}
V_{O}=\frac{V_{O 1}\left(\frac{1}{1-D_{2}}\right)-V_{x}\left(\frac{2+D_{2}}{1-D_{2}}\right)}{\left(1-D_{2}\right)}-2 V_{x}\left(\frac{1}{1-D_{2}}\right) \\
\Rightarrow V_{O}=\frac{V_{O 1}-V_{x}\left(4-D_{2}\right)}{\left(1-D_{2}\right)^{2}}-2 V_{X}\left(\frac{1}{1-D_{2}}\right) \\
\Rightarrow V_{O}=V_{O 1} \frac{1}{\left(1-D_{2}\right)^{2}}-V_{X} \frac{\left(4-D_{2}\right)}{\left(1-D_{2}\right)^{2}}
\end{gathered}
$$

As an approximate response for (6), by neglecting of $V_{X}$ in a simple and close to real state and considering the (3), the output voltage and voltage gain can be written as (7)

$$
G=\frac{V_{o}}{V_{P V}}=\frac{1}{\left(1-D_{1}\right)\left(1-D_{2}\right)^{2}}
$$

By considering the same duty ratio for both power MOSFETs, we can obtain

$$
G=\frac{V_{o}}{V_{P V}}=\frac{1}{(1-D)^{3}},
$$

and by a simple calculation the relation between input and output current values can be calculated as

$$
I_{o}=I_{\text {in }}\left(1-D_{1}\right)\left(1-D_{2}\right)^{2} \stackrel{\text { if } \quad D_{1}=D_{2}}{\longrightarrow} I_{o}=I_{\text {in }}(1-D)^{3} .
$$

\section{Simulation RESUlts}

A group of simulation has been done in MATLAB/SIMULINK, R2017a, for the evaluation and testing of the stability of the proposed circuit. The input voltage for the structure has been fixed in $48 \mathrm{~V}$ DC by consideration of applying a Jiangyin HR-200W-24V type solar panel in our experimental application and output load value has been chosen as 100 ohms. Also, $50 \mathrm{kHz}$ as switching frequency has been considered. Simulation has been done for $50 \%$ of the duty cycle for both blocks and results have been shown in Fig. 4. Table III presents all components and parameters values which have been used in the simulation. For our tests, we assumed the internal resistance for both inductors, $0.16 \Omega$ for inductor $L_{1}$ and 0.1 $\Omega$ for inductors $L_{2}$ and $L_{3}$.

TABLE III. PARAMETERS VALUES OF THE PROJECTED BOOST CONVERTE FOR SIMULATON AND IMPLEMENTATION.

\begin{tabular}{|c|c|}
\hline Parameter & Value \\
\hline Power & $200 \mathrm{~W}$ \\
\hline Input Volatge & $48 \mathrm{~V} \mathrm{DC}$ \\
\hline $\mathrm{L}_{1} / \mathrm{R}_{\mathrm{L} 1}$ & $1.6 \mathrm{mH} / 0.16 \Omega$ \\
\hline $\mathrm{L}_{2}$ and $\mathrm{L}_{3} / \mathrm{R}_{\mathrm{L} 2}$ and $\mathrm{R}_{\mathrm{L} 3}$ & $1 \mathrm{mH} / 0.1 \Omega$ \\
\hline $\mathrm{C}_{1}, \mathrm{C}_{2}$ and $\mathrm{C}_{\mathrm{O}}$ & $220 \mu \mathrm{F}$ \\
\hline $\mathrm{C}_{3}$ & $22 \mu \mathrm{F}$ \\
\hline Duty ratio & $30 \%-90 \%$ \\
\hline Switching Frequency & $50 \mathrm{kHz}$ \\
\hline
\end{tabular}

These simulations have been down for two different structures. For the first block, we considered a conventional boost converter for one of the converters and the proposed structure in this paper for the second converter and for the second block we considered the same block that we considered as our proposed structure for the second block in this study. As Fig. 3(a) shows, the current value that passes through inductor $L_{1}$ is less than classic converter in the same rated power and components values. This can directly decrease the inductor's dynamic loss and improve the total efficiency of the converter. Also, as can be predicted by Table I, the ripple of current for $L_{1}$ is approximately the same for both structures. Figure 3(b) illustrates the inductor $L_{2}$ 's currents and by mathematical proof that is presented in Table I, the ripple of this current is less for proposed converter. Figure 3 has been simulated for a cascaded converter by a conventional boost topology for first block and proposed converter for the second block and the proposed converter for the first and the second blocks. By considering the Fig. 3(c), we can see the same current ripple has been reported for both converters but the average value of current for inductor $L_{3}$ is less than the current value of the classic boost converter. Figure 4(d) illustrates the output current waves for the structures that have been described for Fig. 3(c). As the results of this comparison, it is clear that the quick response can be received by the proposed converter.

Figure 5 presents the voltage gain for the cascade connection for classic boost converter and the proposed converter. For these curves, we considered the same duty cycles for both blocks and as we expected according to mathematical equations presented in Section III, completely higher voltage gains have been obtained for different duty 
cycles.

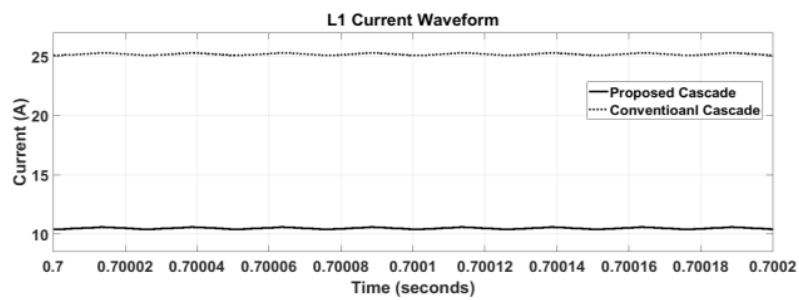

(a)

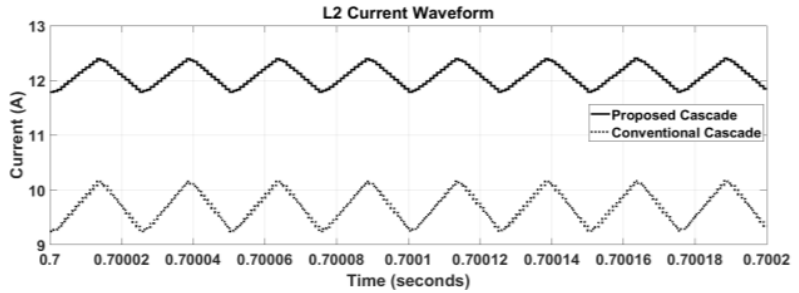

(b)

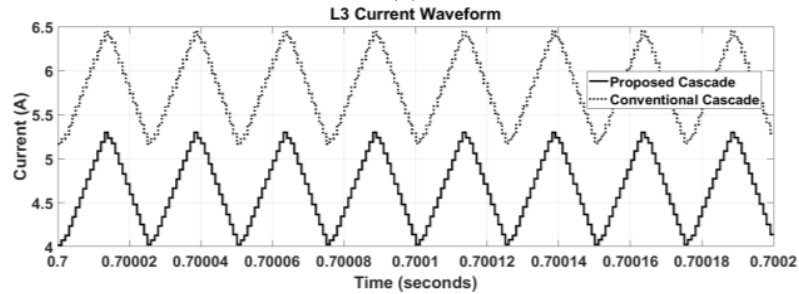

(c)

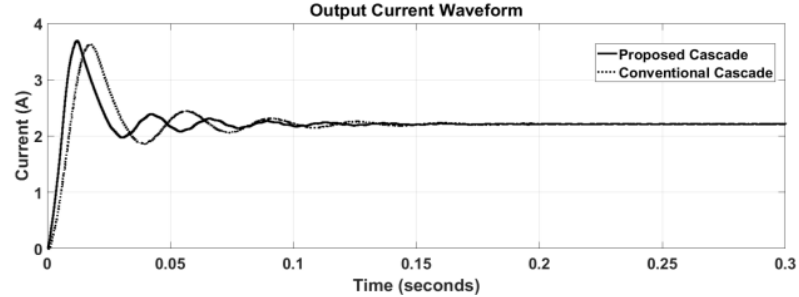

(d)

Fig. 4. Comparison between different parameters of classic and proposed step-up converters based on simulation results: a) first inductor; b) second inductor; c) third inductor's current waveform and; d) output load's current waveform.

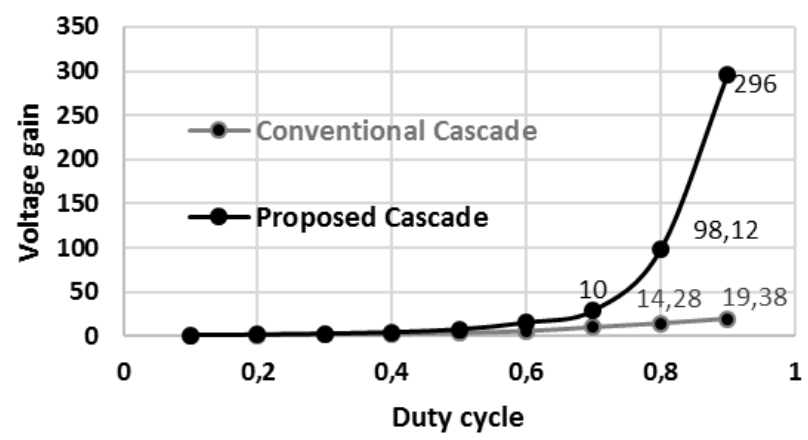

Fig. 5. Voltage gain for both classic and proposed converters.

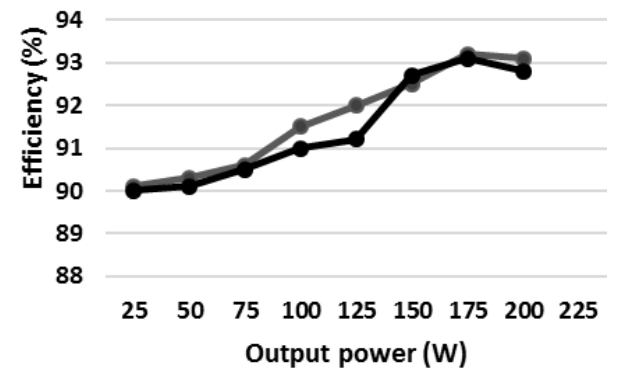

-Conventional Cascade -Proposed Cascade

Fig. 6. Efficiency diagram for classic and proposed cascade converters.
Figure 6 illustrates the efficiency diagram for both converters. For this curve presentation, we considered a $700 \Omega$ till $16 \mathrm{k} \Omega$ resistive load for a fixed $400 \mathrm{~V}$ DC output voltage and $200 \mathrm{~W}$ output rated power. Simulation results proved that for the heavy loads by small resistance and high current values, the proposed structure can give higher current values and efficiency of the proposed converter has been improved.

\section{EXPERIMENTAL RESULTS}

In order to verify the performance of the proposed converter, a $200 \mathrm{~W}$ prototype investigated in the laboratory for $48 \mathrm{~V} \mathrm{DC}$ as input voltage, $380 \mathrm{~V}$ DC as the output voltage and same components values those has been applied in the simulation. For that, we used a $200 \mathrm{~W}-24 \mathrm{~V}$ type solar panel. Figure 7 illustrates the PV panel and the projected converter.
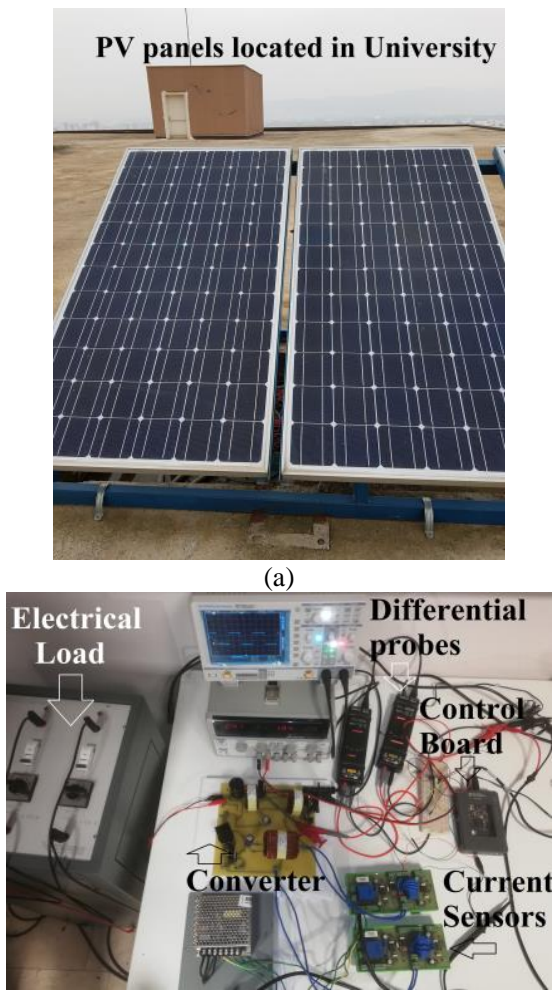

(b)

Fig. 7. The PV panel (a) and the proposed converter (b) with current sensors and control circuit.

The performance of the first block is analysed in Fig. 8.

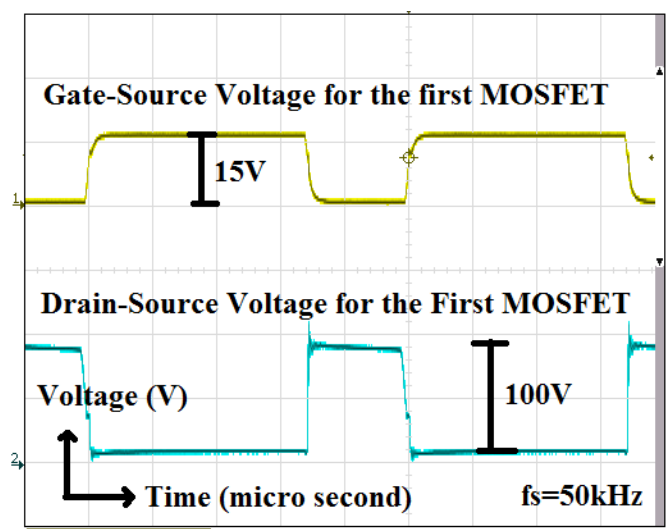

Fig. 8. Performance analysis for the first block's power MOSFET: a) the gain-source voltage and; b) the drain-source voltage waveforms. 
This figure shows that a gate-source signal with $15 \mathrm{~V}$ magnitude, $50 \mathrm{KHz}$ and 70 percent of duty cycle can generate a drain-source signal with around $100 \mathrm{~V}$ peak to peak amplitude, same frequency and 30 percent of the duty cycle. Figure 9 shows the current waveforms for the inductors. As we expected the magnitude of currents completely is matched with the simulation results. This figure shows that when $L_{2}$ is conducting, $L_{3}$ will be off and vice versa.

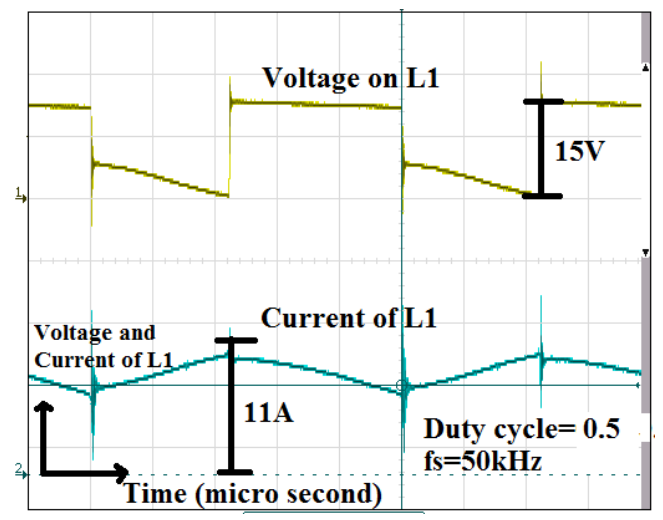

(a)

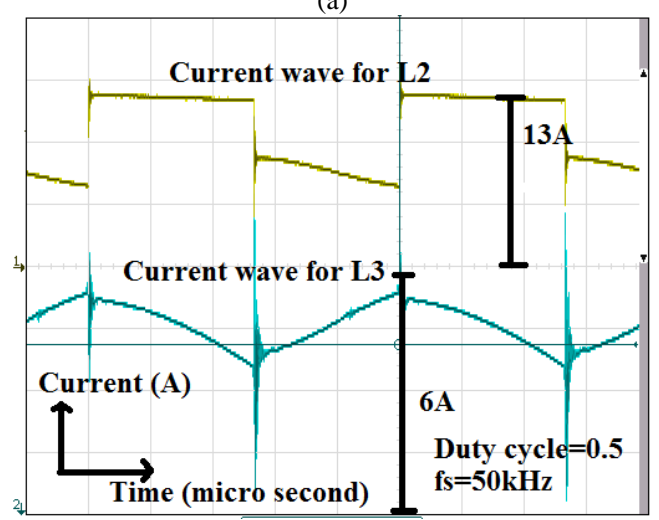

(b)

Fig. 9. Current wave forms for inductors: a) $\mathrm{L}_{1}$; b) $\mathrm{L}_{2}$ and $\mathrm{L}_{3}$.

\section{CONCLUSIONS}

In this study, a high gain cascaded DC-DC converter has been investigated. This structure uses several cheap components including two power MOSFETs, three power diodes, three capacitors, and three inductors. There is a novel structure for the first block to minimize the dynamic losses and improve efficiency. Mathematical, simulation and experimental results are proofing this fact. For the second block, in any time interval of PWM, the circuit current will pass through only one of the diodes, so the efficiency of the projected structure is not impressing. This simple and cheap connection gives a preamplifier specification to the structure, so the proposed converter can give a very high gain compared with a conventional converter. Mathematical analysis shows the projected structure by $10 \mathrm{~V} \mathrm{DC}$ as input voltage can give $1000 \mathrm{~V}$ DC in output by $90 \%$ of duty cycle by considering the ideal components for the converter since it is very important for renewable energy sources where these sources produce a very limited amount of power. The efficiency of the structure is comparable with a conventional boost converter by considering new components switching, dynamic, and frequency losses.

A group of simulation done in MATLAB/SIMULINK $2017 \mathrm{a}$ and results confirmed the theoretical and mathematical analysis. A laboratory scaled prototype has been implemented in $200 \mathrm{~W}$ by applying a Jiangyin HR$200 \mathrm{~W}-24 \mathrm{~V}$ type solar panel and is verifying all mathematical and simulation results. Working in lower switching frequencies will help to decrease voltage and current stresses on power switches where a high gain application is necessary. As a suggestion soft switching and snubber substructures can be utilizable for decreasing these stresses.

\section{REFERENCES}

[1] S. Sathyan, H. M. Suryawanshi, B. Singh, C. Chakraborty, V. Verma, M. S. Ballal, "Zvs-zcs high voltage gain integrated boost converter for dc microgrid", IEEE Trans. Industrial Electronics, vol. 63, no. 11, pp. 6898-6908, 2016. DOI: 10.1109/TIE.2016.2582460.

[2] M. Musbahu, M. Armstrong, M. Elgendy, "A nonisolated interleaved boost converter for high-voltage gain applications", IEEE Journal of Emerging and Selected Topics in Power Electronics, vol. 4, no. 2 , pp. 352-362, 2016. DOI: 10.1109/JESTPE.2015.2488839.

[3] P. Saadat, K. Abbaszadeh, "A single-switch high step-up DC-DC converter based on quadratic boost", IEEE Trans. Industrial Electronics, vol. 63, no. 12, pp. 7733-7742, 2016. DOI: 10.1109/TIE.2016.2590991.

[4] M. Tedesco, A. Cipollina, A. Tamburini, G. Micale, "Towards $1 \mathrm{~kW}$ power production in a reverse electrodialysis pilot plant with saline waters and concentrated brines", Journal of Membrane Sci, vol. 522, pp. 226-236, 2017. DOI: 10.1016/j.memsci.2016.09.015.

[5] M. Tedesco, C. Scalici, D. Vaccari, A. Cipollina, A. Tamburini, G. Micale, "Performance of the first reverse electrodialysis pilot plant for power production from saline waters and concentrated brines", Journal of Membrane Sci, vol. 500, pp. 33-45, 2016. DOI: 10.1016/j.memsci.2015.10.057.

[6] Y. Mei, C.Y. Tang, "Co-locating reverse electro dialysis with reverse osmosis desalination synergies and implications", Journal of Membrane Sci, vol. 539, pp. 305-312, 2017. DOI: 10.1016/j.memsci.2017.06.014.

[7] B. Wu, S. Li, Y. Liu, K. M. Smedley, "A new hybrid boosting converter for renewable energy applications", IEEE Trans. Power Electron, vol. 31, pp. 1203-1215, 2016 DOI: 10.1109/TPEL.2015.2420994.

[8] G. H. F Fuzato, C. R. Aguiar, K. D. A. Ottoboni, R. F. Bastos, R. Q. Machado, "Voltage gain analysis of the interleaved boost with voltage multiplier converter used as electronic interface for fuel cells systems", IET Power Electronics, vol. 9, pp. 1842-1851, 2016. DOI: 10.1049/iet-pel.2015.0598.

[9] M. Forouzesh, K. Yari, A. Baghramian, S. Hasanpour, "Single switch high step-up converter based on coupled inductor and switched capacitor techniques with quasi-resonant operation", IET Power Electronics, vol. 10, no. 2, pp. 240-250, 2017. DOI: 10.1049/ietpel.2015.0923

[10] B. Wn, S. Li, K. M. Smedley, "A new sngle switch isolated high gain hybrid boosting converter", IEEE Trans. Industrial Electronics, vol. 63, pp. 4978-4988, 2016. DOI: 10.1109/TIE.2016.2554542. 